\title{
MANPOWER UTILIZATION IN AEROSPACE
}

\author{
ELI GiNZBERG*
}

INTRODUCTION

The conventional way to distinguish the segments of the American economy is to separate the private profit-seeking sector from the governmental sector. Slightly more detail would provide for nonprofit institutions, such as hospitals and colleges, which operate under voluntary auspices. Since the beginning and particularly the end of World War II another sector has emerged which is difficult to define and delineate sharply. While it formally is part of the private profit-seeking sector, its operations are largely determined by government, and it receives almost all of its income from the sale of goods and services to government. This sector consists of defense contractors, primarily engaged in production of aerospace and research development. Finally, several specialized nonprofit institutions such as Rand, the Research Analysis Corporation, and Mitre devote almost all of their efforts to work which is related to defense.

In our economy, if competition is relatively free and unfettered, it will usually result in a rational allocation of scarce resources and will facilitate the expansion of firms which tend to be the more efficient producers. To the extent that a society permits the consumer to dictate, the market largely decides which goods are produced and in what number. It need act only to protect those without adequate income, and to assure that goods and services essential to the community at large are available. For the most part, the judgment of the market is accepted. This applies not only to the way in which resources are distributed but also to the way in which they are utilized.

Of course, the foregoing is an idealized picture of the American economy. It has long been recognized that our economy is shot through with situations where a few large companies exercise an overwhelming influence on the actions and behavior of those from whom they buy and to whom they sell. Moreover, many of our most important sectors operate under governmental controls which determine the prices which they may charge and the profits they may earn.

What mechanisms, then, do exist to bring about an efficient distribution of scarce resources in the defense industry?

\section{I}

\section{Some Preliminary Observations}

The Armed Forces have long depended on the private enterprise sector of the economy for most of the goods which they use, both in peace and in war. Although

- A.B. I931, A.M. I932, Ph.D. I934, Columbia University. Director, Conservation of Human Resources, Columbia University. Author, Homan Resources: The Wealth of a Nation (I958); Tech- 
the Navy operates a limited number of shipyards and the Army a limited number of arsenals, the primary mission of these service establishments is that of research and development and quality and cost control. This tradition helps to explain why the Navy manufactured aircraft in World War I and why the Army has sought to advance its explorations into space at the Redstone Arsenal. Nevertheless, the Armed Forces have always looked to private enterprise for most of their procurement, including their procurement of weaponry. Hence the question arises, what is new or special about their relations to the aerospace companies?

The answer is both quantitative and structural. In the years preceding the outbreak of World War II, the total expenditures of the Army and the Navy were at a rate of approximately one billion dollars annually, out of a total of about $\$ 9$ billion of federal expenditures when the gross national product averaged about $\$ 90$ billion. The comparable data for 1963 are: $\$ 53$ billion expenditures for national defense (with an additional $\$ 7$ billion for atomic energy and space), out of a total of $\$ 93$ billion of federal expenditures, with a gross national product of $\$ 585$ billion. ${ }^{1}$ These figures imply that prior to World War II, the economic impact of defense spending was insignificant; it comprised a little more than one per cent of the gross national product. Today it is almost ten per cent.

While we could find in our history some parallels to each of these circumstances and conditions, together they represent a unique constellation. A few additional figures will help to set the stage. About half of the expenditures of the Department of Defense, which equal more than $\$ 50$ billion annually, is for personnel and operations and maintenance. Most of the remainder is devoted to procurement, including contracts for research and development. ${ }^{2}$ Of the $\$ 26$ billion prime contract awards in I962, about \$Ig billion went for "hard goods": aircraft, missiles systems, electronic and communications systems, ships, tanks, weapons. ${ }^{3}$ Roughly eighty per cent of the \$Ig billion was spent for the aircraft, missiles, and electronics. ${ }^{4}$

The last years have witnessed a marked drift in the relative expenditures of the Department of Defense between end items and research, development, test and evaluation (RDT\&E). In I956, these RDT\&E awards accounted for less than fourteen per cent of all prime contracts; in the last five years the proportion has risen to between twenty-two and twenty-five per cent. ${ }^{5}$

These expenditures for defense and defense-related activities occurring a decade after the end of the Korean hostilities and almost two decades after the end of World War II, indicate that the relations that have come to be established between the federal government and the aerospace companies may be unique. This contention does not rest on size alone. The following characteristics attest to its validity.

\footnotetext{
nological and Social Change (1964); [with Dale Hiestand and Beatrice Reubens] The Pluralistio Economy (to press 1964 ).

${ }^{2}$ Economic Report of the President 207, 275 (Jan. 1964).

2 Arthur D. Litrle, Inc., How Sick Is the Defense Industry? il (May 1963).

${ }^{8}$ Id. at I2.

'Ibid.

'Id. at 19.
} 
a) The federal government is increasingly purchasing research and development potential rather than hardware, and in this it cannot guide its procurement by the same rules and regulations that it has developed over the years for the purchase of conventional weaponry.

b) The persistence of the Cold War means that the government must be concerned not only about the procurement of a single item or weapons system but about the maintenance of a total defense capability that can be sustained only through continuing large-scale purchases.

c) The scientific and financial management of the current large-scale programs that involve the rapid exploitation of new scientific ideas and technology are without precedent.

d) The fact that the government lets the contracts and pays the bills inevitably opens the decision-making processes to a large number of political considerations and pressures.

e) Inherent in the strenuous efforts that are being made to advance the science and art of weaponry is the fact that relatively little stability can be introduced into contracting relationships between the government and the aerospace companies, Large fluctuations in the value of their defense contracts is a characteristic of aerospace companies.

\section{II}

\section{Some Economic Parameters of Defense}

There are several different ways of looking at the significance of defense procurement for the economy. In terms of total sales of manufacturing companies, defense production accounted for only somewhat over six per cent. The rate is over eight per cent when we consider durable goods alone. ${ }^{6}$ But the impact on particular industries, areas, and companies is very much greater. For instance, all ordnance production and ninety-four per cent of aircraft production is for defense. The proportion of total ship production for defense is about sixty per cent. And even in such a basic civilian industry as electrical machinery about twenty per cent of total output is for military purposes.?

With respect to regions and states, defense production is very heavily concentrated in the Southwest and the West. Although most of the large industrial states of the East and Middle West are engaged in defense production, including research and development, the significance of this effort is much less than in the several western states where it accounts in some states for one-quarter of all manufacturing employment. $^{8}$

Another measure of the significance of defense contracts on particular sectors of the economy is the fact that between one-fifth and one-third of the sales of such

\footnotetext{
- U.S. Bureau of the Census, Statistical Abstract of the United States 258 (1963).

7 Weidenbaum, Economic Adjustments to Disarmament, 22 U. WASH. Bus. REv. 3 ff. (I963).

${ }^{8}$ Id. at 6.
} 
leading manufacturing companies outside of the aircraft industry as General Electric, Westinghouse, Philco, Farm Machinery and Chemical, Minneapolis Honeywell, and still others represents sales to the federal government.

One additional facet of the defense business should be briefly noted at this point. In 1962 just under three-quarters of all prime contracts were let to I00 large corporations. Small businesses, which are defined as those having less than 500 employees, received somewhat less than one-fifth of all prime contracts awarded. Even when allowance is made for the fact that small business receives a substantial number of subcontracts, the extent to which defense work is concentrated in large organizations is pronounced. ${ }^{10}$

These then are the parameters of defense procurement, particularly those defining aerospace. And these are some of the implications that flow therefrom.

(a) The survival and profitability of the areospace companies are dependent on new contracts from the government.

(b) The heavy concentration of the aerospace industry in a few areas makes the economy of these areas very heavily dependent on new contracts.

(c) The sudden cancellation of large defense contracts can have a disastrous effect on particular companies and communities.

(d) Since the determination of awards and, when necessary, the cancellation of defense contracts, must be made by government officials, and since these decisions frequently have a life or death influence on the economic future of particular groups, it is inevitable that the officialdom will be subjected to a great deal of pressure from which there is no full escape in a democratic society.

\section{III}

Some Dimensions of Manpower in Aerospace

At the outbreak of World War II total employment in the aircraft industry amounted to slightly more than 60,000. By the time the United States entered the war it had risen to half a million, or roughly an eight-fold increase in two years. By the end of I943 the total was approaching I.5 million or a further three-fold increase in two years and a 25-fold expansion in four years. By V-J Day the total had shrunk to 325,000 and by 1948 a further decline had reduced it to about 235,000. Thus, a decline of about eighty-five per cent had taken place in five years. By the time of the outbreak of hostilities in Korea the total had climbed to 280,000; thereafter it grew rapidly, and reached about 800,000 as the conflict neared its end. By I957 the figure had crept upward to just short of 900,000. Since then, a slow but steady decline has been taking place. By the end of $196 \mathrm{r}$ total employment in the aircraft industry was about $670,000 .^{11}$

\footnotetext{
${ }^{\circ}$ Staff of Subcomm. on Defense Procurement, Joint Economic Committee, 86th Cong., 2D Sess., Economic Aspects of Mrlitary Procurement and Supply 8 (Comm. Print 1960).

${ }^{10}$ ARthur D. Little Study, op. cit. stipra note 2, at I5.

${ }^{11}$ Aerospace Facts and Figures 64 (American Aviation Publications, Inc., 1962).
} 
Within these general figures are some important qualitative changes. At the height of the World War II expansion, nine out of every ten aircraft employees were production workers. By the time of Korea, only seven of every ten workers were in production; the ratio of engineering and technical personnel had increased substantially. By 1959 less than half of the work force were production workers. The latest figures indicate a further decline; today the proportion is in the neighborhood of forty per cent. ${ }^{12}$

The shift from long-run production of relatively simple aircraft to very short-run production of highly complex jets, and the increasing stress on unique space-craft and on research and development have been reflected in a marked increase in the proportion of both technical and white collar personnel. Currently, technical personnel, including scientists and graduate engineers as well as draftsmen and engineering aides, accounts for twenty-five per cent of the work force. The white collar group below the managerial level accounts for almost the same proportion. The rest are classified as in the management group. To recapitulate: ${ }^{13}$

\begin{tabular}{ll}
\multicolumn{2}{c}{ Percentage } \\
Management & I2 \\
Technical Personnel & 25 \\
White Collar & 23 \\
Production Workers & 40
\end{tabular}

The rapid growth in the numbers of professional personnel employed in aerospace companies is indicated by the following selective data. In 1954 the total number of scientists and engineers was approximately 28,000 ; by 1960 the total was about $65,000-$ an increase of about I20 per cent. The number of engineers increased by about 135 per cent, but the increase in the number of scientists was considerably more rapid: the most conspicuous was the fivefold increase in physicists and the fourfold increase in mathematicians. These two groups combined increased from under 2,000 to over 8,000 in four years. ${ }^{14}$ It is worth noting that roughly two-thirds of all scientists and engineers in aerospace are employed in research and development. ${ }^{15}$

We have already alluded to the extent to which employment in aerospace, and in defense more broadly, is heavily concentrated in a relatively few states and regions. With respect to manpower, we see that in 1960 the three states that comprise the Pacific region had an aerospace payroll of just under \$r.9 billion out of the national total industry payroll of about $\$ 4.6$ billion, or roughly forty per cent. During the preceding five years, a marked shift occurred in the rate of growth and decline of the several regions: the proportion of total defense output produced by the industrial heartland of America-Ohio, Indiana, Illinois, Michigan and Wisconsinwas reduced by about twenty per cent, while the proportion produced by the Western

${ }^{23} \mathrm{Id}$. at 65 .

${ }^{18}$ Ibid.

${ }^{14}$ Ibid.

${ }^{10} \mathrm{Id}$. at $68-69$. 
states, particularly Colorado, increased threefold. The West Coast pushed its relative share higher, as did New England, by about ten per cent. ${ }^{10}$

Another indication of heavy concentration of defense industry is the fact that in two states, Washington and Kansas, employment in defense institutions accounts for over twenty-five per cent of all manufacturing employment, and in five additional Western states-California, Arizona, New Mexico, Utah, and Colorado-it accounts for between fifteen and twenty-five per cent. ${ }^{17}$ The national average is approximately seven per cent. ${ }^{18}$

The substantial fuctuations in total employment and the changes in recent years in the occupational mix suggest that the turnover rate must be relatively high. And so in fact it has been. Accessions have been running between 25 to 30 per 100 per year and separations have fluctuated between 30 and $4^{\circ}$ per Ioo per year..$^{10}$

In brief recapitulation, the manpower position that emerges from this review is one of large-scale total employment fluctuating widely over the years, heavily concentrated in the West and Southwest, shifting rapidly from production workers to technical and white collar workers, with recent rapid increases in the number and proportion of scientists and engineers assigned primarily to research and development work.

\section{IV}

\section{Manpower Utiluzation: Industry Perspectives}

A large number of beliefs and convictions about the aerospace industry have currency. Most of the conventional views are critical and many are held by those in the best position to reach a considered judgment. A first frequently voiced view is that time and again the Armed Forces have launched large-scale programs that had to be scrapped after very large sums and many millions of man-hours had been spent without producing a useful result. Only recently, Secretary McNamara called attention to the billion dollar investment of the Department of Defense in nuclear aircraft that failed. A second charge that is frequently leveled by informed persons relates to the disinclination of those in authority-and this usually refers to both the Congress and the Administration-to cut existing capacity to a level which would meet the present and prospective needs of the Armed Forces. A third criticism refers to the difficulty of cancelling contracts once the evidence has begun to accumulate that the project is off the track and will probably not get back on. Still another serious deficiency is the frequency with which the initially budgeted sums are overrun, not by a modest percentage but by very large amounts. This makes it difficult to allocate resources to what might on balance be much more useful projects. ${ }^{20}$

${ }^{10} \mathrm{Id}$. at 70.

${ }^{17}$ Weidenbaum, supra note 7 , at 6.

${ }^{18}$ U.S. Arms Control and Disarmament Agency, Economic Impacts of Disarasament 25 (ig62),

19 Aerospace Facts and Figures, op. cit. supto note $x \mathrm{r}$, at 72.

${ }^{20}$ Hearings Before the Subcomm. on Defense Procurement of the Joint Economic Comm. Purstuant to Section 5(a) of Public Law 304 (79th Cong.), Impact of Military Stsply and Science Activities on the Economy, 88th Cong., rst Sess. 4 ff., 40 ff. (1963). 
But each of these presumed shortcomings must be assessed in terms of the unique characteristics of the aerospace industry. Many projects which are initiated fail before they reach fruition-there is an estimate of $\$ 6$ billion in cancelled missile projects; but there is no way of developing significant break-throughs in weaponry without taking major risks. While many missile projects have failed, the Polaris program and many others have proved successful. Uncertainty is a basic characteristic of the industry.

A second change supported by a considerable amount of testimony, including the considered opinion of former President Eisenhower, emphasizes excessive capacity. Each service strives constantly for a larger share of the defense dollar, and the defense contractors are their powerful allies. Congressmen from the districts and states that are likely to profit from the appropriations often represent a particularly strong phalanx in advancing the claims of the partisans.

There is no justification for maintaining excess capacity. Nevertheless, Congress does face difficulties in arriving at a determination of the capacity necessary to cope with present and prospective requirements. Although it would be unwise for the government to become dependent on one or even two contractors, it does not follow that all firms that were at one time involved in defense production ought to be kept indefinitely afloat. Yet the letting of contracts to firms in the aerospace industry over these past years conveys the impression that powerful forces are operating to maintain an expanded production capability. Such excess capacity tends to waste dollars and manpower. The rapidly rising defense appropriations of recent years made it relatively easy to protect the excess capacity. If the defense budget levels off or declines, the pressure at least from the Department of Defense for corrective action will increase, because the Department will pay closer attention to its reduced budget.

The present expanded production capability has led the principal competitors to devote a significant proportion of their time and energy to the task of bidding on a great many contracts in the hope of being awarded the one in seven or so which the company must have if it is to survive. As the TFX controversy made clear, the bids are so nearly equivalent that it is exceedingly difficult to reach a determination of potential differentials in performance and price. In such circumstances there is wide scope for political forces to influence the final determination.

To some extent considerations other than market price and performance have been written into law and administrative regulation; these include the set-asides for small business; special advantages for depressed areas; and the obligation of all large government contractors to pursue non-discriminatory policies with respect to the hiring, training, promotion, and separation of their personnel. These provisions imply that the federal government, recognizing that it is engaged in more than the single mission of securing the best defense for the least dollars, is willing within certain narrowly defined limits to use its procurement dollars to assist in the 
realization of other objectives, such as decreasing the rate of unemployment in particular localities or increasing the employment opportunities of minority groups. It is often impossible to draw up an accounting system that would reveal in dollar and manpower terms whether these additional objectives have resulted in a net social gain or loss. But this much is certain: the larger the number and variability of the criteria, the more difficult is the task of the awarding agency in reaching a determination.

A summary judgment of these efforts at this time is that the Department of Defense has found it very difficult to increase materially the share of the procurement dollar which goes to depressed areas or small business, but it has made considerable progress in the last few years to elicit the cooperation of the larger contractors in expanding employment opportunities for minority group members.

Beyond these specific social objectives there is another aspect of defense procurement that carries broad implications for manpower utilization. We have noted that the awarding of contracts to particular firms or their cancellation frequently results in substantial changes in the economic life and particularly the employment patterns of the communities in which the prime contractor and principal subcontractors are located.

In many instances when a contract is let, the community must build or expand its public and private facilities to cope with the added population and labor force. Expansion is generally a pleasant, even an exhilarating experience. The secondary costs are relatively easy to absorb. But contraction is the reverse.

When the Skybolt program was terminated in 1963 over 5,200 people were laid off within a month and a half. ${ }^{21}$ About 3,000 were let go by Northrop Nortronics at Hawthorne, California; and Douglas Aircraft released the remainder, most of whom were professional, clerical, or skilled workers. ${ }^{22}$ With employment relatively strong on the Coast, this cut-back was absorbed without too much difficulty. But the question arises as to the consequences that would follow upon a cut-back which affected several major programs at the same time. Such a development could undermine the economic foundation of a defense area in short order.

The serious local disturbances that can follow upon a cut-back help to explain why government officials are loath to cancel a program until they are forced to. Moreover, every cut-back and cancellation carries with it implicit criticism of its original protagonists and sponsors as well as those who had the responsibility for monitoring it along the way. It is easier for a large bureaucratic structure, especially one which faces eventual congressional inquiry, to let matters slide in the hope that time will somehow take care of them rather than to take action which carries with it overt acknowledgment of error or failure.

These are some of the complex factors inherent in the nature of aerospace in-

${ }^{11}$ Hearings Before the Subcomm. on Employment and Manpower of the Senate Comm. on Labor and Public Welfare, on Nation's Manpower Revolution, 88th Cong., Ist Sess. pt. 7, at 2425 (1963).

22 Id. at 2427 . 
dustry operating within a governmental contracting structure that make it difficult indeed to avoid situations where scarce manpower resources tend to be ineffectively utilized. But this is but one dimension of a two-faceted problem. We must also consider the impact of government contracting on manpower utilization from the vantage point of the individual aerospace company.

\section{$\mathrm{V}$}

\section{Manpower Utilization: Company Perspectives}

How does the problem of manpower utilization look when the focus is shifted from the Department of Defense to the individual contractor? A first observation is that heavy reliance on cost-plus-fixed-fee contracts encourages a series of wasteful manpower practices, such as high recruitment costs and other costs that result from hoarding of personnel, excessive overtime, over-classification, and other actions that tend to raise labor costs. While the government was able to bring many of the more wasteful practices under administrative control by placing limits on reimburseable costs, these administrative approaches still leave much to be desired. For those on the inside are frequently able to hide more than those on the outside are able to find. And if the two become equally skilled, much time and effort can be spent by one party's making a ploy which the other party succeeds in thwarting with little productive return to either.

In fact the tendency of the government contracting officer to adhere strictly to the book and to hesitate to grant exceptions to the terms of the contract, which often sets unreasonably high specifications, contributes to wastefulness. Moreover, although the federal government is one, the contracting agencies are many-the Department of Defense, each of its four services, NASA, AEC, and still others. Many contractors work for many customers each one of whom has different objectives and different operating procedures though they all use the tax dollar to pay their bills.

We cannot place a quantitative measure on the scope for improved utilization of manpower which could result from a contracting relationship with more freedom built into it. Elasticity in contracting could only prevail under preconditions of competence and sophistication such as is characteristic of many large units that buy and sell to each other in the competitive arena. But proximate equality of competence does not generally prevail in the area of government contracting. Hence the inclination, almost the necessity, of many government agencies to rely upon rules and regulations.

The way in which contracts are written helps to explain the many untoward developments in.wage and salary structures and in utilization practices. In periods of rapid expansion in defense work there were strong forces leading to excessive mobility among professional and other personnel; the principal aim of the individual was to improve his classification and earnings through job shifts. Where the government agreed to cost-plus-fixed-fee contracts there was much less pressure 
on employers than would exist in normal competitive markets for moderating increases in wage and salaries. Moreover, the ability of a contractor to compete for additional work was strengthened if he could demonstrate that he had on his payroll a part of the essential manpower resources required for staffing the new projects. This led to overstaffing or hoarding, especially of types of personnel which might be hard to find in a tight labor market. Since contractors received a fee which was customarily a percentage of their total allowable costs, there was little incentive for them to exercise caution and restraint in the hiring of personnel or in the salaries that they were able or willing to pay them.

There were, however, several constraints on the hoarding of personnel and the concomitant rise in salary and wage levels. Government regulations finally disallowed certain types of recruiting and other costs. Further, the employer who was overstaffed could never be certain that he would in fact receive a new contract or, in the event he did not, that he would be able to assign the surplus workers to existing contracts. Moreover, to hire additional personnel at wage and salary levels that were considerably above those received by the regular work force could lead to pressures for increases across the board. Finally, in the face of a relatively level or even declining labor force such as has been characteristic of the industry in recent years, carrying personnel in excess of present requirements was much too costly.

The relatively small number of large defense contractors on the West Coast engaged in aerospace has led to a marked degree of cooperation among them with respect to both wage and salary policy and other personnel practices and to helping each other balance their manpower requirements and staffs. From many points of view the whole of the West Coast from San Diego to Seattle must be viewed as a single labor market. When a firm is awarded a contract, it usually needs to hire many additional personnel. However, several others had probably bid on the same contract; they might be ready to release personnel whom they had held while the award was in question. The personnel departments of the large contractors have frequently helped each other to smooth the transfers between the hiring firm and those who were releasing personnel.

On balance we can conclude that the system of government contracts, which places heavy reliance on cost-plus-fixed-fees, contributed substantially to wasteful manpower practices but that action has been taken in recent years both by the government and the aerospace companies to bring many of the excrescences under control. The forces operating in favor of more effective utilization are gaining in strength but the standard still falls short of that in competitive markets.

These considerations have dealt with manpower in general in aerospace without reference to qualitative differentials. However, the key to many manpower problems lies in their qualitative manifestations and changes. During the last quarter century the aerospace industry has made three major transitions: from piloted aircraft, to missiles, to space craft. When account is taken of the several stages in the 
sophistication of piloted aircraft from two and four piston engines to advanced jets, the number of radical adjustments has been considerably greater. Radical changes in output called for significant changes in manpower. These transitions would have been much slower and less smooth had it not been that the training and retraining costs undertaken by the industry were viewed by the government as a reimburseable expense.

We can now see additional difficulties about reaching a balanced judgment about the true social costs and benefits inherent in the contracting system in aerospace. The federal government underwrote large training and retraining costs; a complete balance sheet would also have to include the expenditures of the state of California for supplementary educational and training support. Reimbursement of the contractor has facilitated much of the mobility of personnel at the professional level that has come to characterize the industry.

The costs of training and retraining came high, and so did those connected with enticing and transporting to California large numbers of professional personnel from other parts of the country. Private entrepreneurs would have been much more restricted in securing and maintaining a vital labor force, since they would have had to cover most of those costs themselves.

\section{VI}

\section{Manpower Utulzation: Combined Perspectives}

As noted earlier, the rapid advances in military and space technology and the increasing costliness of weapons systems have made it even more important that government reach sound decisions about which technological leads to follow up and which to eschew. But unlike with the purchase of commodities in established markets, the government is not able to assess the relative advantages of these systems since generally they do not exist but must be designed and developed. The task of the government here actually is to assess the relative research and development potential of competing concerns. This task has important manpower implications. Since it is short of competent research and development personnel in its own ranks, the government has sought to broaden and deepen its ability to make sound judgments through a series of devices that include heavy reliance on contracting with nonprofit institutions to help in the blueprinting of new approaches and in the assessment of competing proposals. The government has also made heavy use of expert consultants from academic life and the business community. While these efforts of the government have been as necessary as they have been sound, this approach does have limitations. The number of qualified consultants in this field is relatively small and almost all have some stakes direct or indirect in the matters concerning which they give advice. There is considerable competition among profit-seeking aerospace companies, the universities, and various specialized nonprofit defense organizations for the research and development dollar. 
Most economists would agree that substantial excess capacity supported by public or private funds will inevitably result in the widespread wasteful use of resources. Most political scientists would agree that it is difficult to secure speedy legislative and administrative support for cutting back government installations once they become redundant. The first question that arises then is the extent to which mechanisms exist to make a sensible determination of the amount of capacity required to meet the present and prospective needs of the government for defense; then we must determine to take action to shrink that capacity if it is found to be excessive. For unless there is a reasonable balance between capacity, including stand-by capacity for emergency need, and requirements the waste of manpower and other resources will be substantial.

Closely related to the foregoing is the question of the adequacy of existing mechanisms to help guide the allocation of prime contracts among different firms and different localities. It is reasonably clear that the gravamen of decision-making has been in terms of current research and production capability, because of the Defense Department's inevitable concern with time. This has led to heavy concentration both corporate and geographic. Yet as the period of the Cold War lengthens there may be opportunity to draw up a comprehensive balance sheet in which social costs and benefits previously excluded from the decision-making process might be included. For the federal government has heavy responsibility beyond defense, and its defense and space procurement policies affect the incidence of unemployment, the opportunity of minority groups to secure employment, the tendencies toward excessive corporate power, the broadening of the nation's research potential, and still other important national objectives. The objective here is to improve the balancing of short and long run considerations in which the primary concern of defense and space procurement is considered within a more complete framework, which will include such factors as whether the defense capability of the United States could be made stronger as a result of alterations in the present pattern of procurement.

The burden of this analysis has been to emphasize that since the end-products of aerospace are used overwhelmingly by government, since the prices are negotiated by government, since the profits are determined by government-the government has, or surely could have, the major role in determining how the industry uses its manpower resources. Considerable evidence has been noted that suggests that there is marked scope for improvement on many fronts and that the government must soon assume greater responsibility for assessing the broader aspects of manpower utilization in aerospace because of its importance both for defense and for economic growth and stability.

A review of the last quarter century reveals a striking elasticity in the relationships among government, profit-seeking enterprise, and nonprofit institutions which has permitted this nation to meet its most urgent defense and space needs through improvisation. But this has involved very large costs in manpower and dollars. 
Existing mechanisms are not adequate substitutes for the competitive market. The magnitude and impact of the relations of government to defense contractors justify public attention. American capitalism has shown a great capacity to undergo modifications as conditions and circumstances require. Here is a new sector that still must be fitted into the broad framework of our economy and society if it is to make a maximum contribution at minimum cost. 